\title{
Resilience, Depression, Anxiety, and Stress among Overseas Filipino Seafarers
}

\author{
Jane Marie D. Tamayo \\ Health Metrics Inc.-Iloilo, Iloilo City, Philippines \\ jainetamayo@gmail.com
}

\begin{abstract}
This descriptive-correlational study assessed the level of resilience, depression, anxiety and stress among overseas Filipino seafarers and its relationship to demographic variables such as age, marital status, length of service, position category, and family structure. Also, it sought to find out if resilience is associated with depression, anxiety, and stress, respectively. Sixty-six overseas Filipino seafarers were obtained through convenience and snowball sampling in Iloilo. The data were gathered using the Brief Resilience Scale (BRS) and Depression, Anxiety, Stress Scale (DASS-21) and were analyzed using percentage, mean, Fisher Exact test, and Pearson-r product. The results showed normal level of resilience and experience normal levels of depression, anxiety, and stress. There is no relationship between resilience, depression, anxiety, stress and the demographic profiles. Moreover, resilience is negatively associated with depression, anxiety, and stress. Results of the study served as a basis for resilience enhancement and distress management program for overseas Filipino seafarers.
\end{abstract}

Keywords: Resilience, Depression, Anxiety, Stress, Overseas Filipino Seafarers, Iloilo City, Philippines 